\title{
Prescribing Errors With Low-Molecular-Weight Heparins
}

\author{
Marielle Slikkerveer, PharmD, * Afke van de Plas, PharmD, * Johanna H.M. Driessen, PhD, * + f \\ Robin Wijngaard, * Frank de Vries, PharmD, PhD, *†f Renske Olie, MD, $\$ / /$ \\ Nathalie Meertens,// and Patricia van den Bemt, PharmD, PhD $/$
}

\begin{abstract}
Background: Low-molecular-weight heparins (LMWHs) are used in the prevention and treatment of venous thromboembolism (VTE). Bleeding is the primary major complication of LMWH therapy, which is associated with dose. The administration of appropriate dosages of LMWHs depends on the patient's risk of VTE, risk of bleeding, bodyweight, and renal function. Therefore, LMWH prescribing is prone to errors. However, no earlier study has explored the frequency of prescribing errors with LMWH.

Purpose: The aim of the study was to determine the frequency and determinants of in-hospital LMWH-prescribing errors.

Methods: A cross-sectional study was conducted to examine the frequency and determinants of LMWH prescribing errors between April and August 2014. We randomly selected 500 patients 18 years and older with at least one LMWH prescription during inpatient hospitalization. A prescribing error was a deviation from the internal hospital guidelines. Logistic regression estimated determinants of prescribing error.

Results: A prescribing error was present with $34 \%$ of all LMWH users. The most frequently recorded error was a dose that was not adjusted to body weight and/or renal function (85\%). Prophylactic LMWH prescribing in medical wards was associated with a higher risk of prescribing error as compared with surgical wards.

Conclusions: The frequency of prescribing errors was $34 \%$ in a tertiary care hospital. Being a patient with prophylactic LMWH use on a medical ward is a determinant for LMWH prescribing error. Interventions that will lead to better electronic recording of body weight and more awareness among medical doctors may reduce the total number of prescribing errors.
\end{abstract}

Key Words: anticoagulants, heparin, low molecular weight, medication errors, prescriptions, safety

( Patient Saf 2021;17: e587-e592)

$V^{2}$ nous thromboembolism (VTE) is a common but preventable complication of hospitalization and a potentially lethal disease. ${ }^{1}$ Compared with the general population, patients who are hospitalized have a greater than 100-fold increased risk of acute VTE. ${ }^{2}$ Risk factors for VTE are common among hospitalized patients and include age, major surgery, immobilization, cancer, and trauma. ${ }^{3-6}$ Venous thromboembolism is the third leading cause of cardiovascular mortality in Europe. ${ }^{1}$ Deaths that occur as a consequence of

From the *Department of Clinical Pharmacy and Toxicology, Maastricht University Medical Center+; †School CAPHRI, Maastricht University, Maastricht; tDepartment of Pharmacoepidemiology \& Clinical Pharmacology, Utrecht University, Utrecht, the Netherlands; §Department of Internal Medicine, ||Thrombosis Expertise Center, Maastricht University Medical Center+, Maastricht; and $\mid$ Department of Hospital Pharmacy, Erasmus University Medical Center, Rotterdam, the Netherlands.

Correspondence: Frank de Vries, Department of Clinical Pharmacy and Toxicology, Maastricht University Medical Centre+, Maastricht, the Netherlands (e-mail: frank.de.vries@mumc.nl).

The authors disclose no conflict of interest.

M.S., P.B., and F.V. had substantial contributions to the conception or design of the work, F.V. had substantial contributions to the acquisition, J.D. and R.W. had substantial contributions to analysis, and M.S., A.P., J.D., R.W., F.V., R.O., N.M., and P.B. had substantial contributions to the data for the work. M.S., A.P., J.D., R.W., F.V., R.O., N.M., and P.B. drafted the work or revising it critically for important intellectual content. M.S., A.P., J.D., R.W., F.V., R.O., N.M., and P.B. had the final approval of the version to be published. Copyright (C) 2017 Wolters Kluwer Health, Inc. All rights reserved. hospital-acquired VTE comprise $71 \%$ of the total number of VTErelated deaths in six European countries. ${ }^{1}$ Pulmonary embolism patients are especially at high risk for death. Untreated acute pulmonary embolism is associated with a mortality rate of up to $25 \%{ }^{7}$

Despite direct oral anticoagulants are increasingly used for VTE prophylaxis in patients after knee and hip surgery, fondaparinux and low-molecular-weight heparins (LMWHs) are still the cornerstone of VTE prophylaxis in hospitalized patients. ${ }^{8,9}$ Besides thrombosis prophylaxis, LMWHs are also used in therapeutic dosages for treatment of VTE or as so-called "bridging therapy" in patients on vitamin K antagonists who have to interrupt this therapy because of planned invasive procedures. ${ }^{8-10}$ Administration of inappropriate dosages of LMWHs can lead to serious complications: overdosage may cause major bleeding, but on the contrary, underdosage of LMWHs may lead to inadequate prevention of VTE events. ${ }^{11}$ When prescribing the appropriate dosage of LWMHs, the treating physician should not only decide whether a prophylactic or therapeutic dosage is needed but also should take into account patient-related factors such as bleeding risk, body weight, and renal function. ${ }^{12}$ Reduced renal clearance of LMWHs in patients with renal insufficiency may lead to accumulation of the LMWH and stronger anticoagulation effects as a result, which can lead to serious adverse events such as bleeding. ${ }^{13}$ Patients using enoxaparin had a 2- to 3-fold increased risk of major bleeding when they experienced severe renal insufficiency (creatinine clearance $\leq 30 \mathrm{~mL} / \mathrm{min}$ ), as compared with patients with normal renal function. ${ }^{14}$ This is important to note, because moderate renal insufficiency has been reported in a quarter of medical inpatients in tertiary care hospitals, and approximately $10 \%$ experience severe renal insufficiency. 15

Therefore, prescribing LMWHs may be complex and prone to errors. However, no earlier study has explored the frequency of prescribing errors with LMWHs. Insight into potential risk factors of these prescribing errors is necessary to prevent prescribing errors. Several potential risk factors were identified in studies on prescribing errors in general. Type of hospital ward ${ }^{16,17}$ and age $e^{18,19}$ were examples of identified potential risk factors. Nevertheless, it is unknown whether these also apply to prescribing errors with LMWHs. Therefore, the aim of this study was to determine the frequency and determinants of in-hospital LMWH prescribing errors.

\section{METHODS}

\section{Source Population}

This cross-sectional study was conducted at the department of clinical pharmacy of a tertiary care hospital in Maastricht, the Netherlands, between April and August 2014. All wards (except the intensive care units) used a computerized physician order entry system (CPOE), which includes real-time checks on prescribing errors such as underdosages and overdosages and drug interactions (VCD Pharma, the Netherlands). It could also track and trace every prescription from the time of prescribing up to administration, which is electronically confirmed by nursing staff. Furthermore, the hospital kept electronic medical records (EMRs) for every patient. 
TABLE 1. Recommended Tinzaparin Dosages for Therapeutic Use According to Body Weight and Renal Function

\begin{tabular}{|c|c|c|c|c|}
\hline Body Weight, kg & Frequency & $\mathrm{eGFR} \geq 60^{*}$ & eGFR 30-60* $*^{\dagger}$ & eGFR $\leq 30^{*}$ \\
\hline$\leq 60$ & Once daily & $10,000 \mathrm{IU}$ & $7000 \mathrm{IU}$ & $5000 \mathrm{IU}$ \\
\hline $60-80$ & Once daily & $14,000 \mathrm{IU}$ & $10,000 \mathrm{IU}$ & $7000 \mathrm{IU}$ \\
\hline $80-100$ & Once daily & $18,000 \mathrm{IU}$ & $14,000 \mathrm{IU}$ & $10,000 \mathrm{IU}$ \\
\hline $100-120$ & Once daily & $20,000 \mathrm{IU}$ & $14,000 \mathrm{IU}$ & $10,000 \mathrm{IU}$ \\
\hline $120-140$ & Once daily & $24,000 \mathrm{IU}$ & $18,000 \mathrm{IU}$ & 10,000 or $14,000 \mathrm{IU}$ \\
\hline $140-160$ & Once daily & $28,000 \mathrm{IU}$ & $20,000 \mathrm{IU}$ & $14,000 \mathrm{IU}$ \\
\hline
\end{tabular}

*Units: $\mathrm{mL} / \mathrm{min} / 1.73 \mathrm{~m} 2$.

${ }^{\dagger}$ Based on a $25 \%$ dosage reduction of tinzaparin, with dosages round up to commercially available preparations, if possible.

${ }^{*}$ Based on a $50 \%$ dosage reduction of tinzaparin, with dosages round up to commercially available preparations, if possible.

Physicians prescribed electronically by selecting the drug's substance name, its daily dose, administration route, and administration frequency in the CPOE. A patient's body weight could be registered by nurses in the structured "vital signs section" of the EMR, or it could be written as free text in the medical notes by physicians. In addition, physicians, pharmacists, or other authorized staff could record body weight in the CPOE, but this was not obligatory. Renal function was registered in the laboratory test section of the EMR.

\section{Study Population}

From April 2014 through August 2014, 500 patients 18 years and older who had been prescribed LMWH either in prophylactic or therapeutic dosage during their hospitalization were randomly selected. In our hospital guideline, once-daily nadroparin is the LMWH of choice for prophylactic indications, whereas for therapeutic indications, the physician can either choose once-daily tinzaparin or twice-daily nadroparin. Other LMWHs were not available in the hospital. When a patient was hospitalized more than once, we randomly selected one hospitalization episode. During each hospitalization, every patient was followed from the date of his first LMWH prescription until the date of discharge, death, or occurrence of outcome, whichever came first. For nadroparin, the time until the subsequent administration was determined to define whether nadroparin was prescribed in a twice-daily therapeutic regimen (i.e., the time between two administrations was $<18$ hours) or in a prophylactic once-daily regimen (i.e., the time between two administrations was $\geq 18$ hours). Patients whose LMWH prescription was discontinued before the LMWH was administered or in whom we could not determine whether a therapeutic or prophylactic dosage was prescribed were excluded. In addition, we excluded patients on intensive care units, because they did not use the CPOE system.

\section{Other Variables}

Baseline characteristics were determined at the first LMWH prescription. The most recently recorded body weight was extracted from the vital signs section of the EMR. Only in case of a missing body weight, the medical notes and CPOE were reviewed for the most recently recorded body weight. When two or more different values for body weight were recorded on the same day, the highest value was used. All renal functions were extracted from the electronic laboratory test results. The estimated glomerular filtration rate (eGFR) was estimated from serum creatinine levels using the Modification of Diet in Renal Disease formula (MDRD).

Patients were hospitalized in different nursing wards. For this study, we decided to divide these wards into two main categories: medical wards and surgical wards. Medical wards included internal medicine, gastroenterology, rheumatology, pulmonology, endocrinology, cardiology, and neurology. Surgical wards included general surgery, orthopedics, ophthalmology, oral and maxillofacial surgery, dermatology, plastic surgery, urology, cardiothoracic surgery, as well as gynecology and obstetrics. Oncology patients were hospitalized in the ward depending on their type of malignancy and could be treated on either surgical or medical wards.

\section{The LMWH Dosing Scheme}

Therapeutic and prophylactic weight-based standard doses for tinzaparin and nadroparin were derived from the internal hospital prescribing guidelines, as shown in Tables 1 to 3. In our hospital, reduced dosages for all therapeutic $\mathrm{LMWH}$ in patients with moderate (MDRD 30-60 mL/min/1.73 $\mathrm{m}^{2}$ ) to severe (MDRD-eGFR $<30 \mathrm{~mL}$ / $\mathrm{min} / 1.73 \mathrm{~m}^{2}$ ) renal insufficiency are prescribed empirically. According to the current guidelines of the Dutch Nephrology Federation, this dosage reduction comprises $25 \%$ and $50 \%$ for moderate and severe renal insufficiency, respectively. ${ }^{20}$ Prophylactic dosages were not adjusted in case of renal insufficiency. For patients on prophylactic

TABLE 2. Recommended Nadroparin Dosages for Therapeutic Use According to Body Weight and Renal Function

\begin{tabular}{llcc}
\hline Body Weight, kg & Frequency & eGFR $\geq \mathbf{6 0}^{*}$ & eGFR 30-60*广 \\
\hline$\leq 50$ & Twice daily & $3800 \mathrm{IU}$ & $2850 \mathrm{IU}$ \\
$50-70$ & Twice daily & $5700 \mathrm{IU}$ & $3800 \mathrm{IU}$ \\
$70-110$ & Twice daily & $7600 \mathrm{IU}$ & $5700 \mathrm{IU}$ \\
$\geq 110$ & Twice daily & $9500 \mathrm{IU}$ & $7600 \mathrm{IU}$ \\
\hline
\end{tabular}

*Units: $\mathrm{mL} / \mathrm{min} / 1.73 \mathrm{~m}^{2}$.

${ }^{\dagger}$ Based on a $25 \%$ dosage reduction of nadroparin, with dosages round up to commercially available preparations, if possible.

${ }^{*}$ Based on a $50 \%$ dosage reduction of nadroparin, with dosages round up to commercially available preparations, if possible. 
TABLE 3. Recommended Nadroparin Dosages for Prophylactic Use According to Body Weight

\begin{tabular}{lccc} 
Body Weight, kg & Frequency & Regular Dose & Intermediate Dose* \\
\hline$\leq 70$ & Once daily & $2850 \mathrm{IU}$ & $5700 \mathrm{IU}$ \\
$70-90$ & Once daily & $3800 \mathrm{IU}$ & $7600 \mathrm{IU}$ \\
$\geq 90$ & Once daily & $5700 \mathrm{IU}$ & $7600 \mathrm{IU}$ \\
\hline
\end{tabular}

*Intermediate dose for patients with estimated high VTE risk.

dosages, the prescribing physician can choose, based on the patientrelated VTE risk, between the regular prophylactic dosage and an intermediate dosage.

\section{Outcome}

The primary outcome was the first prescribing error with LMWH during follow-up. A prescribing error was defined as a deviation from the internal hospital guidelines regarding one of the following aspects.

For therapeutic LMWH users, (1) the prescribed dosage was not adjusted to body weight and/or renal function according to the internal hospital guidelines (Tables 1 or 2), or (2) body weight was not electronically recorded in the past 365 days before LMWH prescribing, or (3) the eGFR was unknown or it was considered unreliable (i.e., when a value $>60 \mathrm{~mL} / \mathrm{min} / 1.73 \mathrm{~m}^{2}$ was recorded $>1$ year ago or when a value $<60 \mathrm{~mL} / \mathrm{min} / 1.73 \mathrm{~m}^{2}$ was recorded $>2$ weeks ago). For prophylactic LMWH users, a prescription error was counted either when the dosage was not adjusted to body weight according to the hospital's internal guidelines (Table 3) or when body weight was not electronically recorded in the past 365 days before LMWH prescription.

\section{Statistical Analyses}

Descriptive statistics was used to determine the frequency of prescribing errors.

In a subsequent analysis, the association of several potential risk factors (age, sex, ward type, prophylactic versus therapeutic LMWH use) with the outcome was determined. In addition, results were stratified for prophylactic or therapeutic use.

Logistic regression was used to investigate whether ward type, age, sex, and prophylactic/therapeutic dosage of LMWH were associated with a prescribing error, using SAS 9.2 software (SAS Institute, Carey, NC).

\begin{tabular}{|c|c|}
\hline & $\begin{array}{l}\text { Study population } \\
\quad \mathrm{N}=500\end{array}$ \\
\hline \multirow[t]{2}{*}{$\begin{array}{l}\text { Excluded } \\
\text { - Patients whose LMWH } \\
\text { prescription was discontinued } \\
\text { before the LMWH was } \\
\text { administered }(\mathrm{n}=20) \\
\text { - Patients, of whom we could not } \\
\text { determine if dosing was therapeutic } \\
\text { or prophylactic }(\mathrm{n}=49) \\
\text { - Patients on intensive care units } \\
(\mathrm{n}=13)\end{array}$} & \\
\hline & $\begin{array}{l}\text { Patients included in } \\
\text { analysis ( } \mathrm{n}=418)\end{array}$ \\
\hline
\end{tabular}

FIGURE 1. Study population flow chart.
This is an observational study and according to Dutch national legislation (Wet Medisch Wetenschappelijk Onderzoek met Mensen [legislation for medical scientific research, involving humans]) not subject to ethical approval.

\section{RESULTS}

A total of 500 patients were randomly selected between April 2014 and August 2014. Of these 500 patients, 82 were excluded from analysis with the following reasons: LMWH was discontinued before first dose was administered $(n=20)$, no information on therapeutic or prophylactic dosing scheme $(n=49)$, and patients admitted on intensive care units $(\mathrm{n}=13)$ (Fig. 1). Thus, for our analysis, we included 418 patients.

TABLE 4. Baseline Characteristics of LMWH Users*

\begin{tabular}{|c|c|}
\hline Characteristics & LMWH Users \\
\hline No. patients & 418 \\
\hline No. women & $211(50.5)$ \\
\hline Age, mean (SD), y & $62.0(17.0)$ \\
\hline \multicolumn{2}{|l|}{ Age, y } \\
\hline$<50$ & $79(18.9)$ \\
\hline $50-69$ & $190(45.5)$ \\
\hline$\geq 70$ & $149(35.6)$ \\
\hline Body weight, mean (SD), kg & $77.0(17.5)$ \\
\hline \multicolumn{2}{|l|}{ Body weight, kg } \\
\hline$<50$ & $11(2.6)$ \\
\hline $50-69$ & $122(29.2)$ \\
\hline $70-89$ & $178(42.6)$ \\
\hline $90-109$ & $71(17.0)$ \\
\hline$\geq 110$ & $17(4.1)$ \\
\hline Not recorded & $19(4.5)$ \\
\hline Duration of admission, mean (SD), d & $9.9(7.9)$ \\
\hline \multicolumn{2}{|l|}{ Regime } \\
\hline Prophylactic & $358(85.6)$ \\
\hline Therapeutic & $60(14.4)$ \\
\hline \multicolumn{2}{|l|}{ Drug } \\
\hline Tinzaparin & $42(10.0)$ \\
\hline Nadroparin & $376(90.0)$ \\
\hline \multicolumn{2}{|l|}{ Ward type } \\
\hline Medical $^{\dagger}$ & $146(34.9)$ \\
\hline Surgical ${ }^{*}$ & $272(65.1)$ \\
\hline \multicolumn{2}{|l|}{ Most recently recorded eGFR } \\
\hline \multicolumn{2}{|l|}{ By time interval } \\
\hline$<14 \mathrm{~d}$ ago & $314(75.1)$ \\
\hline $15-365 \mathrm{~d}$ ago & $66(15.8)$ \\
\hline$>365 \mathrm{~d}$ ago & $0(0.0)$ \\
\hline Not recorded & $38(9.1)$ \\
\hline \multicolumn{2}{|l|}{ By value } \\
\hline $\mathrm{eGFR} \geq 60 \mathrm{~mL} / \mathrm{min} / 1.73 \mathrm{~m}^{2}$ & $286(68.4)$ \\
\hline eGFR $30-60 \mathrm{~mL} / \mathrm{min} / 1.73 \mathrm{~m}^{2}$ & $76(18.2)$ \\
\hline $\mathrm{eGFR} \leq 30 \mathrm{~mL} / \mathrm{min} / 1.73 \mathrm{~m}^{2}$ & $18(4.3)$ \\
\hline Not recorded & $38(9.1)$ \\
\hline \multicolumn{2}{|c|}{ *Data are presented as $\mathrm{n}(\%)$, unless stated otherwise. } \\
\hline \multicolumn{2}{|c|}{$\begin{array}{l}\text { †Medical wards included internal medicine, cardiology, gastroenterology, } \\
\text { neurology, psychiatry, endocrinology, pulmonology, and rheumatology. } \\
\text { 'Surgical wards included orthopedic, urology, ophthalmology, plastic } \\
\text { surgery, and gynecology. }\end{array}$} \\
\hline
\end{tabular}


TABLE 5. Clinical Prescribing Errors by Sex, Substance, Ward, and Renal Function*

\begin{tabular}{|c|c|c|c|}
\hline Type & $\begin{array}{c}\text { All Errors } \\
(\mathrm{N}=142)\end{array}$ & $\begin{array}{l}\text { Error With Prophylactic LMWH } \\
\qquad(\mathrm{n}=117)\end{array}$ & $\begin{array}{l}\text { Error With Therapeutic LMWH } \\
\qquad(\mathrm{n}=\mathbf{2 5})\end{array}$ \\
\hline \multicolumn{4}{|l|}{ Sex } \\
\hline Female & $67(47.2)$ & $52(44.4)$ & $15(60.0)$ \\
\hline Male & $75(52.8)$ & $65(55.6)$ & $10(40.0)$ \\
\hline \multicolumn{4}{|l|}{ Drug } \\
\hline Nadroparin & $125(88.0)$ & $117(100.0)$ & $8(32.0)$ \\
\hline Tinzaparin & $17(12.0)$ & $0(0.0)$ & $17(68.0)$ \\
\hline \multicolumn{4}{|l|}{ Ward type } \\
\hline Medical & $57(40.1)$ & $48(41.0)$ & $9(36.0)$ \\
\hline Surgical & $85(59.9)$ & $69(59.0)$ & $16(64.0)$ \\
\hline \multicolumn{4}{|l|}{ Renal function by eGFR } \\
\hline $\mathrm{eGFR} \geq 60 \mathrm{~mL} / \mathrm{min} / 1.73 \mathrm{~m}^{2}$ & NA & NA & $6(24.0)$ \\
\hline eGFR $30-60 \mathrm{~mL} / \mathrm{min} / 1.73 \mathrm{~m}^{2}$ & NA & NA & $15(60.0)$ \\
\hline $\mathrm{eGFR} \leq 30 \mathrm{~mL} / \mathrm{min} / 1.73 \mathrm{~m}^{2}$ & NA & NA & $1(4.0)$ \\
\hline Not recorded & NA & NA & $3(12.0)$ \\
\hline
\end{tabular}

Patient characteristics are shown in Table 4. The mean age of the LMWH users was 62.0 years, and the proportions of men and women were comparable. The LMWH users had a mean body weight of $77.0 \mathrm{~kg}$ and the mean duration of the admission was 9.9 days. A total of $65.1 \%$ of the patients were admitted to a surgical ward. Low-molecular-weight heparins were mainly prescribed in a prophylactic dosage $(85.6 \%)$, and nadroparin was the most prescribed LMWH (90\%). Of the 60 patients $(14.4 \%)$ with a therapeutic regime, 42 patients used tinzaparin and 18 patients used nadroparin. Estimated glomerular filtration rate was not recorded in 38 patients, and more than $75.1 \%$ of the patients had their renal function recorded in 2 weeks before baseline. Renal insufficiency was reported in $22.5 \%$ of LMWH users.

We found that $34.0 \%$ of LMWH prescriptions contained a prescribing error. The most frequently recorded error was a dose that was not adjusted to body weight and/or renal function (84.5\%), followed by lack of electronic recording of body weight $(12.7 \%)$. Only three patients with a therapeutic regime had missing data for renal function and one patient had an unreliable eGFR. Table 5 shows the prescribing errors by sex, substance, ward, and renal function.
Table 6 shows that age, sex, ward, and therapeutic or prophylactic use were not significantly associated with risk of a prescribing error. Prophylactic LMWH prescribing in medical wards was associated with a higher risk of prescribing error as compared with surgical wards, when stratified for prophylactic or therapeutic LMWH prescription (Table 6). The risk further increased after the addition of the type of LMWH use (prophylactic/ therapeutic use) to the multivariate model (Table 7).

\section{DISCUSSION}

This study showed that prescribing errors of LMWHs are common in a Dutch tertiary care hospital. In this study, $34.0 \%$ of all LMWH prescriptions had a clinical prescribing error. Most prescribing errors with LMWH treatment included overdosages and underdosages that were not adjusted to body weight or renal function, followed by missing data on body weight. Almost every therapeutic LMWH user had a reliably recorded renal function. Overall risk factors of prescribing errors were not identified. When we stratified prescribing errors into prophylactic or therapeutic LMWH use, we found that among prophylactic

TABLE 6. Potential Risk Factors of Prescribing Errors of Tinzaparin or Nadroparin; Stratified for Prophylactic or Therapeutic LMWH Prescription

\begin{tabular}{|c|c|c|c|}
\hline \multirow[t]{2}{*}{ Exposure } & \multicolumn{3}{|c|}{ Adjusted OR (95\% CI) } \\
\hline & All Errors & Prophylactic LMWH Errors & Therapeutic LMWH Errors \\
\hline \multicolumn{4}{|l|}{ Age, y } \\
\hline$<50$ & Reference & Reference & Reference \\
\hline $50-69$ & $1.08(0.62-1.89)$ & $0.98(0.54-1.77)$ & $2.42(0.36-16.40)$ \\
\hline$\geq 70$ & $1.20(0.68-2.13)$ & $0.92(0.49-1.73)$ & $3.58(0.54-23.78)$ \\
\hline Female sex* & $0.79(0.52-1.18)$ & $0.65(0.41-1.02)$ & $2.06(0.74-5.74)$ \\
\hline Medical ward ${ }^{\dagger}$ & $1.44(0.95-2.18)$ & $1.65(1.04-2.63)$ & $0.64(0.23-1.78)$ \\
\hline $\begin{array}{l}\text { Adjusted for } \\
\text { * Reference: } \mathrm{r}^{\dagger} \text { Reference: s } \\
\text { CI, confidenc }\end{array}$ & in the table. & & \\
\hline
\end{tabular}


TABLE 7. Potential Risk Factors of Prescribing Errors of Tinzaparin or Nadroparin, Including Type of LMWH use

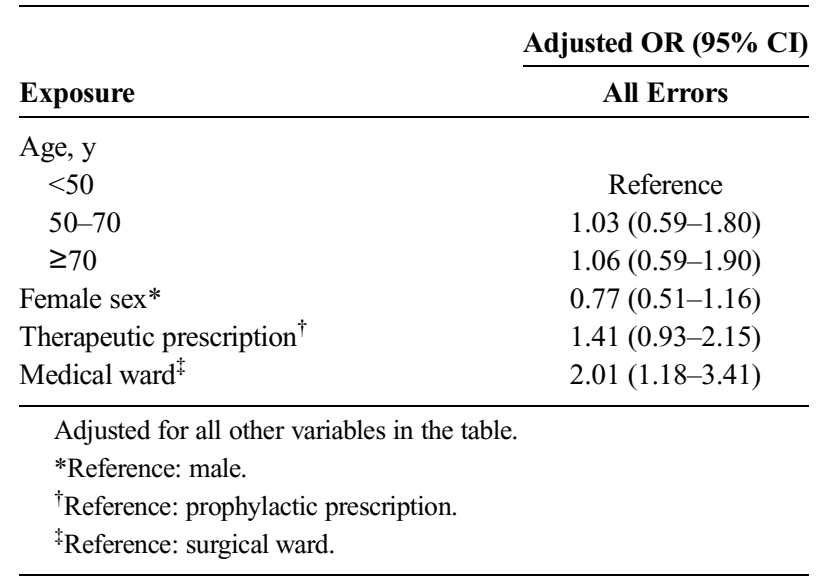

users, admission on a medical ward was more associated with prescribing errors than on a surgical ward. This was also shown, when the type of LMWH use was added to the multivariate model.

This is probably the first study that specifically evaluated prescribing errors with LMWHs. A previous study that was conducted in a US tertiary care hospital in Boston, Massachusetts, showed a 350-fold lower proportion of all medication errors with LMWH (including prescribing errors) as compared with our study. ${ }^{21}$ This substantial difference is probably caused by a difference in the methods of data collection: the previous study obtained medication errors that were self-reported, whereas we retrospectively evaluated routinely collected electronic medical records. On the other hand, our study may have overestimated the true number of clinical prescribing error because we also considered missing electronic data on, for example, body weight or renal function as prescribing errors, whereas this information may have been discussed during the consultation. A cross-sectional study among hospitalized patients in Argentina ${ }^{22}$ showed that adherence to VTE prophylaxis guidelines was inadequate for $28 \%$ of the patients' prescriptions. This number is in keeping with our finding that $29.1 \%$ of patients with a recorded body weight had been prescribed an incorrect prophylactic dose of LMWHs. We do not have information on patients that had an indication for LMWH prophylaxis but in whom mistakenly no LMWH was prescribed. In the previously mentioned study, these patients were also included in the $28 \%$ inadequate prescriptions.

Our findings on potential risk factors of clinical prescribing errors with LMWH treatment are in line with those from an epidemiological study that evaluated prescribing errors for all classes of drugs in two Dutch teaching hospitals in the Netherlands. ${ }^{16}$ Both studies showed that patient's age and sex were not associated with prescribing or dosing errors. In literature, we found differences in ward type as risk factor for clinical prescribing errors. ${ }^{23,24}$ In a study in eight hospitals of Scotland, surgical wards were associated with a higher risk of prescription errors; however, in a three center study in the United Kingdom, medical wards were more associated with errors. Other risk factors such as prescriber characteristics (e.g., experience or age) or drug characteristics could explain these differences.

Comparing the reported incidence of prescribing errors is difficult because it varies and depends on the definition of prescribing error. ${ }^{25}$

Our definition of prescribing errors included mainly dosing errors and was based on deviations from our internal hospital guideline regarding LMWH dosing. For prophylactic LMWH, these hospital guidelines recommend LMWH prescribing based on several patient-related factors, including assessment of the patients individual VTE risk, based on, for example, previous VTE, known thrombophilia, or active malignancy. For these high-risk patients, instead of the regular prophylactic dosage, an intermediate LMWH dosage could be prescribed. Information on this baseline VTE risk is not routinely recorded in the EMR and could therefore not be evaluated. This may have resulted in underestimation of errors with prophylactic LMWH treatment, because we considered nadroparin dosages that could be prescribed prophylactically for both low- or intermediate-risk VTE patients as correct. Our hospital dosing guideline comprises weight-based dosing of LMWH for both therapeutic and prophylactic prescriptions. For prophylactic LMWH, this weight-based dosing is not universally applied in all hospitals. This might have introduced more prescribing errors, because physicians might not be familiar with this weight-based dosing of prophylactic LMWH. For therapeutic LMWH, weight-based dosing is a common practice. We did not validate the electronic recording of body weight; for example, it is unknown whether this had been measured or whether it was based on self-report. When body weight was not recorded, we could not check whether the dose administered was correct or incorrect. Therefore, we had to count this as a prescribing error, while it was possible that the patient had received the right dose, based on verbal information that was not recorded in the EMR. This might have caused an overestimation of the prescribing errors in our study. An EMR should be designed in a way that recording patient data, such as body weight, is obligatory. In our hospital, a dosage reduction of $25 \%$ and $50 \%$ is implemented for moderate and severe renal insufficiency, respectively, according to the recommendations of the Dutch Federation of Nephrology. ${ }^{20}$ Nevertheless, the underlying evidence for these recommendations is weak: treatment with tinzaparin and nadroparin has infrequently been studied in patients with renal insufficiency ${ }^{10,14}$ and recommendations regarding dosage reduction and/or anti-Xa monitoring vary. ${ }^{26}$

Our study had several strengths. To our knowledge, it is the first report of prescribing errors with LMWHs. We showed that there is need for improvement based on the high proportion of prescribing errors. We also identified the number of missing patient characteristics such as body weight and renal function of LMWH users as a source of possible prescribing errors. We used a welldefined protocol with a clear definition of prescribing errors. The medical prescriptions were extracted directly from the CPOE retrospectively, without the knowledge of the physicians at moment of prescribing, which has decreased the likelihood of selection bias.

Our study had several limitations as well. We did not compare the incidence of outcomes such as VTE or bleeding with prescribing errors of LMWHs. Other studies showed that $1.5 \%$ to $2.7 \%$ of all heparin-related medication errors involved patient harm. ${ }^{27,28}$ We also did not check whether the anti-Xa concentration was determined and/or correct or whether the prescribing doctor had a specific reason to derogate from the hospital guideline (e.g., bleeding risk of a patient). Although medical doctors in this hospital should be aware of and comply with internal LMWH prescribing guidelines, the results from our study suggest that this may have not been the case.

In conclusion, the frequency of prescribing errors was $34 \%$ in a tertiary care hospital. Being a patient with prophylactic LMWH use on a medical ward is a determinant for LMWH prescribing error. Interventions that will lead to better electronic recording of body weight and more awareness among medical doctors, in particular when prescribing therapeutic LMWH treatment, may reduce the total number of prescribing errors. A more effective way to improve the prescribing of LMWHs can be found in more hardwired solutions, such as a Clinical Decision Support System, which contains two or more items of patient data and which generates a patient specific advice to the doctor. 


\section{REFERENCES}

1. Cohen AT, Agnelli G, Anderson FA, et al. Venous thromboembolism (VTE) in Europe. The number of VTE events and associated morbidity and mortality. Thromb Haemost. 2007;98:756-764.

2. Heit JA, Melton LJ 3rd, Lohse CM, et al. Incidence of venous thromboembolism in hospitalized patients vs community residents. Mayo Clin Proc. 2001;76:1102-1110.

3. Anderson FA Jr, Weeler HB, Goldberg RJ, et al. The prevalence of risk factors for venous thromboembolism among hospital patients. Arch Intern Med. 1992;152:1660-1664.

4. Heit JA, Silverstein MD, Mohr DN, et al. Risk factors for deep vein thrombosis and pulmonary embolism: a population-based case-control study. Arch Intern Med. 2000;160:809-815

5. Martinelli I, Bucciarelli P, Mannucci PM. Thrombotic risk factors: basic pathophysiology. Crit Care Med. 2010;38:S3-S9.

6. Goldhaber SZ, Bounameux H. Pulmonary embolism and deep vein thrombosis. Lancet. 2012;379:1835-1846.

7. Barritt DW, Jordan SC. Anticoagulant drugs in the treatment of pulmonary embolism. a controlled trial. Lancet. 1960;1:1309-1312.

8. Kearon C, Akl EA, Comerota AJ, et al.; Antithrombotic Therapy for VTE disease: Antithrombotic Therapy and Prevention of Thrombosis, 9th ed: American College of Chest Physicians Evidence-Based Clinical Practice Guidelines. Chest. 2012;141:e419S-e496S.

9. CBO-richtlijn: Diagnostiek, preventive en behandeling van veneuze trombo-embolie en secundaire precentie arteriële trombose. 2008.

10. Federatie Nederlandse Trombosediensten (FNT). De kunst van het doseren. Richtlijn, leidraad en informatie voor het doseren van vitamine $\mathrm{K}$ antagonisten. 2010.

11. Levine MN, Raskob G, Landefeld S, et al. Hemorrhagic complications of anticoagulant treatment. Chest. 2001;119:108S

12. Johansen KB, Balchen T. Tinzaparin and other low-molecular-weight heparins: what is the evidence for differential dependence on renal clearance? Exp Hematol Oncol. 2013;8:2-21.

13. Farooq V, Hegarty J, Chandrasekar T, et al. Serious adverse incidents with the usage of low molecular weight heparins in patients with chronic kidney disease. Am J Kidney Dis. 2004;43:531-537.

14. Lim W, Dentali F, Eikelboom JW, et al. Meta-analysis: low-molecular-weight heparin and bleeding in patients with severe renal insufficiency. Ann Intern Med. 2006;144:673-684.
15. Schmid P, Fischer AG, Wuillemin WA. Prevalence of impaired renal function in medical inpatients. Swiss Med Wkly. 2007;137:514.

16. Fijn R, Van den Bemt PM, Chow M, et al. Hospital prescribing errors: epidemiological assessment of predictors. Br J Clin Pharmacol. 2002;53: 326-331.

17. Ho L, Brown GR, Miilin B. Characterization of errors detected during central order review. Can J Hosp Pharm. 1992;45:193-197.

18. Vrca VB, Becirevic-Lacan M, Bozikov V, et al. Prescribing medication errors in hospitalised patients: a prospective study. Acta Pharm. 2005;55: 157-167.

19. Lesar TS, Lomaestro BM, Pohl H. Medication-prescribing errors in a teaching hospital. A 9-year experience. Arch Intern Med. 1997;157: 1569-1576.

20. Nederlandse Federatie voor Nefrologie. Richtlijn Antistolling met LMWH bij nierinsufficiëntie. Nieuwegein: 2012.

21. Fanikos J, Stapinski C, Koo S, et al. Medication errors associated with anticoagulant therapy in the hospital. Am J Cardiol. 2004;94:532-535.

22. Bottaro FJ, Ceresetto JM, Emery J, et al. Cross-sectional study of adherence to venous thromboembolism prophylaxis guidelines in hospitalized patients. The Trombo-Brit study. Thromb J. 2012;10:7.

23. Grissinger MC, Hicks RW, Keroack MA, et al. Harmful medication errors involving unfractionated and low-molecular-weight heparin in three patient safety reporting programs. Jt Comm J Qual Patient Saf. 2010;36:195-202.

24. Franklin BD, Reynolds M, Shebl NA, et al. Prescribing errors in hospital inpatients: a three-centre study of their prevalence, types and causes. Postgrad Med J. 2011;87:739-745.

25. Franklin BD, McLeod M, Barber N. Comment on 'prevalence, incidence and nature of prescribing errors in hospital inpatients: a systematic review'. Drug Saf. 2010;33:163-165.

26. Garcia DA, Baglin TP, Weitz JI, et al. Parenteral Anticoagulants: Antithrombotic Therapy and Prevention of Thrombosis, 9th ed: American College of Chest Physicians Evidence-Based Clinical Practice Guidelines. Chest. 2012;141:e24S-e43S.

27. Ryan C, Ross S, Davey P, et al. Prevalence and causes of prescribing errors: the Prescribing Outcomes for Trainee Doctors Engaged in Clinical Training (PROTECT) study. PLoS One. 2014;9:e79802.

28. Desai RJ, Williams CE, Greene SB, et al. Anticoagulant medication errors in nursing homes: characteristics, causes, outcomes, and association with patient harm. J Healthc Risk Manag. 2013;33:33-43. 